\title{
Determinants of Caregiver Burden in Early-Onset Dementia
}

\author{
Annalisa Chiari ${ }^{a}$ Barbara Pistoresi ${ }^{b}$ Chiara Galli ${ }^{a, c}$ Manuela Tondelli ${ }^{a, c}$

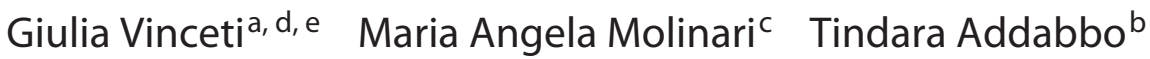 \\ Giovanna Zamboni ${ }^{a}$, $, e, f$
}

aU.O. Neurologia, Azienda Ospedaliero Universitaria di Modena, Modena, Italy; ${ }^{b}$ Dipartimento di Economia Marco Biagi, Università di Modena e Reggio Emilia, Modena, Italy; 'Dipartimento di Cure Primarie, AUSL Modena, Modena, Italy; ${ }^{d}$ Dipartimento di Scienze Biomediche, Metaboliche e Neuroscienze, Università di Modena e Reggio Emilia, Modena, Italy; ${ }^{e}$ Center for Neurosciences and Neurotechnology, Università di Modena e Reggio Emilia, Modena, Italy; fNuffield Department of Clinical Neurosciences, University of Oxford, Oxford, UK

\section{Keywords}

Alzheimer's dementia · Caregiver burden · Early-onset Alzheimer's disease · Frontotemporal dementia · Young-onset dementia

\begin{abstract}
Introduction: Caregivers of patients with early-onset dementia (EOD) experience high levels of burden, which is known to be affected by caregivers' psychological features as well as by patients' and caregivers' demographical and social variables. Although potential clinical, demographical, and social determinants have been separately examined, it is not known how they reciprocally interact. Methods: Ninety-two consecutive patient-caregiver dyads were recruited from the Cognitive Neurology Clinics of Modena, Northern Italy. Caregivers were asked to fill in questionnaires regarding their burden, psychological distress, and family economic status. Data were analyzed with multivariable regression models and then entered in a mediation model. Results: Caregiver burden was positively related to female caregiver sex, spousal relationship to the patient, severity of patient's behavioral symptoms, diagnostic delay, and financial distress of the family. It was negatively related to disease dura-
\end{abstract}

karger@karger.com www.karger.com/dee

Karger $\stackrel{\text { ' }}{=}$
(C) 2021 The Author(s)

Published by S. Karger AG, Basel

This is an Open Access article licensed under the Creative Commons Attribution-NonCommercial-4.0 International License (CC BY-NC) (http://www.karger.com/Services/OpenAccessLicense), applicable to the online version of the article only. Usage and distribution for commercial purposes requires written permission. tion, patient's education, region of birth, caregiver age, number of caregiver's days off work, number of offspring, and caregiver perception of patient's quality of life. While the effect of caregiver age, diagnostic delay, and of proxies of family or social network directly impacted on caregiver's burden, the effect of patient's disease duration, being a wife caregiver, financial distress, and number of caregiver's days off work was entirely mediated by the level of caregiver psychological distress. Conclusions: Both direct actions (such as increasing social networks and shortening diagnostic delay) and indirect actions aimed at reducing psychological distress (such as increasing the number of caregiver's days off work and financial support) should be planned to reduce caregiver's burden.

(C) 2021 The Author(s). Published by S. Karger AG, Basel

\section{Introduction}

The term "early-onset dementia" (EOD) indicates dementia with symptom onset before the age of 65 , irrespectively from the type of underlying dementia syndrome. From a clinical point of view, EOD differs substantially from late-onset dementia because it frequently presents 
with atypical syndromes [1], has a more aggressive clinical course and higher mortality [2], and is associated with lower life expectancy [3]. In addition, EOD has greater impact on patients and their families because it affects people who are still engaged in social, working, and parental life. Recent studies have shown that the challenges faced by patients with EOD and their caregivers are specific [4]. They are related to the difficulty in reaching a correct diagnosis, which in turn is associated with greater diagnostic delay [5], the impact of the diagnosis on family members, especially on offspring who may still be young [6], and the consequences on patients and caregivers' jobs [7]. Dementia care networks are usually tailored on older patients with different clinical syndromes and social background and therefore do not fit EOD patients' needs [8].

Although caregiver psychological distress measured, as an example, with the Relative Stress Scale [9] is a specifically psychological construct, caregiver burden is a complex multidimensional construct composed by aspects inherent to the caregiver - such as their personal psychological wellbeing - but also by nonpsychological factors, unrelated to the caregiver and depending on the patient's specific symptoms as well as on the availability of external support [10-12]. Severe burden is a serious condition for caregivers, associated with high risk of medical comorbidity, which can be effectively reduced by specific interventions aimed at reducing either the psychological or nonpsychological components of burden, or both $[13,14]$. Caregiver burden occurs at higher levels in dementia compared to other medical illnesses [15] and is even greater in caregivers of EOD patients $[16,17]$. It has socioeconomical consequences not only for patients and their families but also for the whole society [18].

Several studies have investigated the determinants of burden of caregivers of people with all-age dementia. They have shown that burden is associated with factors related to the clinical features of the patient including presence of behavioral and psychological disorders (BPSD), degree of impairment on instrumental activities of daily living, type of dementia syndrome, and severity of cognitive impairment [19-21]. Other studies have shown that burden may be related to demographical factors such as the age and sex of the caregiver, social factors such as the amount of social interactions or availability of practical support [22], health literacy, training, and financial factors such as costs of care [23]. Fewer studies have specifically investigated these determinants in EOD, confirming the significant effect of BPSD [24-26]. However, no previous studies have studied the role of clinical, de- mographical, social, and financial factors as potential determinants of EOD caregiver burden together in a comprehensive way.

In the present study, we investigated multiple potential determinants of EOD caregiver burden and specifically studied how they interact in affecting the psychological and nonpsychological components of caregiver burden, with the ultimate aim of disentangling the determinants that can be modified by specific interventions $[8$, 27]. We hypothesized that social and financial factors would more likely affect nonpsychological components of burden, whereas clinical and demographical factors might affect the psychological components of caregiver burden.

\section{Methods}

Ninety-two consecutive eligible patients with EOD and their caregivers were recruited from the Cognitive Neurology Clinics of the province of Modena, Emilia Romagna region in Northern Italy, from February 2017 to October 2019. Patients with a dementia diagnosis with symptom onset before age 65 underwent extended clinical, imaging, and neuropsychological assessment. Their caregivers underwent a structured face-to-face interview to gain information on their burden (Zarit Caregiver Inventory $[10,28]$ ), psychological distress (Relative Stress Scale, RSS [9]), on patients' neuropsychiatric symptoms (Neuropsychiatric Inventory [29]) functional impairment (Alzheimer's Disease Cooperative Study Activities of Daily Living, ADCS-ADL [30]), and their perception of the patient's quality of life (QoL-AD, Quality of Life-Alzheimer Disease [31]). Cumulative illness rating scale (CIRS [32]) was used to assess patient's comorbidities. Patients' place of birth allowed establishing whether they were born inside or outside the Emilia Romagna region, which was used as a proxy of the extension of the social network, assuming that a patient living in the same region where he was born in has a larger social network. The number of offspring was considered a proxy of the extension of the family network. The answer to a specific item of RSS (item 11: "in the last 4 weeks, how often have you had the feeling of not having enough money to care for the patient in addition to the rest of the expenses?") was extracted and used as a proxy of the family economic status. The caregiver's number of days off work in the previous month was recorded as well as the type of services the patient and families took advantage of (cognitive or speech therapy, day center, psychologic counseling, and respite care facilities).

Descriptive statistics were applied to investigate the clinical and global cognitive measures of patients and the demographic and social measures of patients and caregivers. Nonnormal variables were square-, log-, or square root-transformed as appropriate, and univariate regression analyses were applied to investigate the association between social, demographic, clinical, and cognitive measures and caregiver burden. The variables were then entered in multivariable regression models to comprehensively identify the determinants of caregiver burden and their interactions. We used OLS multiple regression analysis controlling for no severe collinearity among the regressors computing the variance inflation 
Table 1. Patients' and caregivers' characteristics

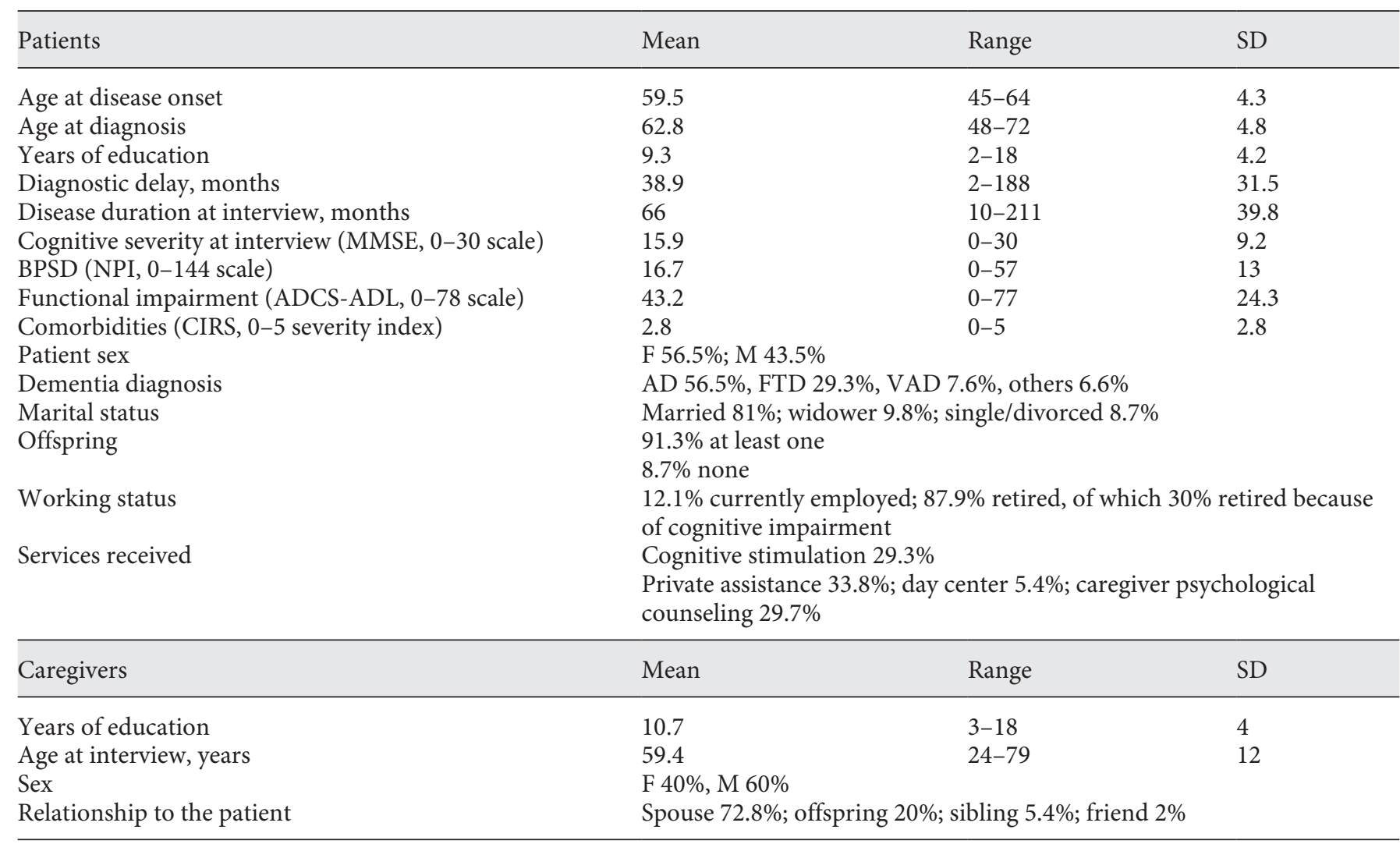

factor. Robust standard errors were applied. The econometric strategy compared nested specifications, where every regression model included different blocks of variables: patient and caregiver demographics, clinical, social, and financial variables.

We subsequently analyzed a mediation model to explore whether the effect of some of the determinants of burden could be mediated by psychological distress. First, we studied the relationship between all the identified determinants of burden and caregiver's psychological distress. Second, we accounted for the influence of psychological distress (the mediator in our analysis) on caregiver's burden. Finally, we assessed the role of the determinants of burden once the mediator was also entered into the analysis. In other terms, the total effect $C$ of each determinant of the burden was decomposed into a direct effect $c^{\prime}$ and indirect/mediated effects $\left(a\right.$ and $b$ ), so that $C=c^{\prime}+a \times b$. All statistical analyses were performed with STATA software for Mac, version 14 .

\section{Results}

Data from 92 EOD patient-caregiver dyads were examined. Among the patients, 52 were females. Mean age at EOD onset was 59.5 years (SD 4.3, range 45-64), and mean education was 9.3 years (SD 4.2, range 2-18).
Among all patients, 56.5\% had Alzheimer's dementia, $29.3 \%$ one of the diseases of the FTD spectrum, $7.6 \%$ vascular dementia, and $6.6 \%$ other dementia diagnoses. Among all patients, $81 \%$ were married, $9.8 \%$ were widowers, and $8.7 \%$ were single or divorced. As for number of offspring, $8.7 \%$ had none, whereas the remaining had at least one. A percentage of $87.9 \%$ patients were retired at the time of assessment and among these 30\% had left work because of the dementia. Cognitive stimulation or speech therapy had been offered to $29.3 \%$ of patients, $33.8 \%$ had received private assistance at home, and 5.4\% had attended a day center.

Among the caregivers, 37 were females. Mean age was 59.4 years (SD 12, range 24-79) and mean education 10.7 years (SD 4, range $3-18$ ). $72.8 \%$ of caregivers were the patients' spouses, whereas the remaining were children (20\%), siblings $(5.4 \%)$, or friends $(2 \%)$. Among all caregivers, $29.3 \%$ had had access to psychological counseling. Table 1 reports the clinical and demographic features of patients and the demographic features of caregivers.

Using the OLS multiple regression method, model 1 emerged, in which all the included independent variables 
Table 2. Results of multivariable OLS regression models

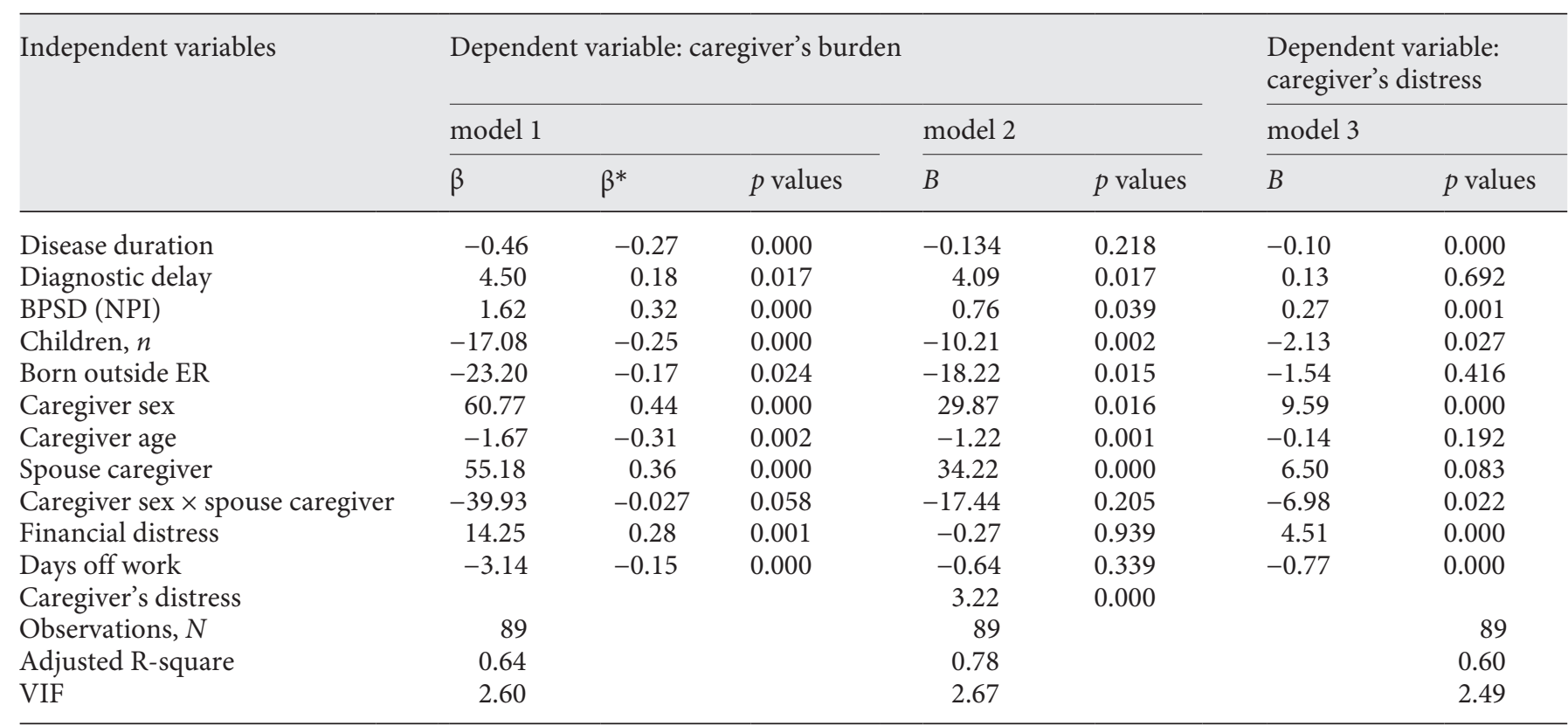

Robust standard errors are applied. VIF $<10$ indicates no severe collinearity among the regressors. Jarque-Bera test $\left(\mathrm{H}_{0}: \mathrm{normality}\right.$ of residuals): model $1 p=0.55$, model $2 p=0.36$, and model $3 p=0.92$, hence we do not reject the null. $\beta$, unstandardized coefficients; $\beta^{*}$, standardized coefficients.

were found to be significant in determining caregiver burden. It explained $64 \%$ of the total variance. Table 2 gives information for the independent variables entered into model 1 (also shown in Fig. 1) and outlines both unstandardized and standardized coefficients. Standardized coefficients were used to allow considering size effects of the determinants on caregiver burden. Caregiver burden was positively related to diagnostic delay, severity of BPSD, female caregiver's sex, spousal relationship of the caregiver, and the perceived reduction in financial means. In the same model, burden was negatively related to caregiver age, disease duration (i.e., time elapsed since symptom onset at the time of interview), patients' years of education, patient's quality of life as perceived by the caregiver, number of offspring, living in the same region where they were born in, and number of days off work taken by the caregiver. Moreover, there was a significant interaction between caregiver sex and caregiver relation to the patient in that being the patient's sister or daughter was associated with higher burden than being the patient's wife, which in turn was associated with higher burden than being a male caregiver.

Figure 1 shows the results of the mediation model testing whether the effect of the identified determinants of burden could be mediated by caregiver psychological distress (mediator). More precisely, it shows the relationship between the identified burden determinants and the mediator (path $a$ ), the influence of the mediator on caregiver burden (path $b$ ), and finally the role of the determinants of burden once the mediator was also entered into the analysis (path $c$ ).

Model 3 (path $a$ in Fig. 1) describes the estimated relationship between the determinants of caregiver burden and caregiver psychological distress as a dependent variable. All the determinants of caregiver burden are important in determining caregiver psychological distress, with the exception of diagnostic delay, social network (i.e., being born in the Emilia Romagna region), and caregiver age.

Model 2 (path $b$ in Fig. 1) describes the influence of psychological distress (the mediator in our analysis) on caregiver burden. The results showed that psychological distress is highly significant and positively related to caregiver burden. Finally, model 2 also depicts the relationship between caregiver burden (as a dependent variable) once the mediator was also entered into the analysis (path $c$ in Fig. 1). The outcome highlighted that when the mediator was taken into account, some variables highly sig- 
Fig. 1. Graphic representation of the me-

- Disease duration

- Diagnostic delay

- BPSD

- Patient QoL

- Patient education

- Number od offspring

- Social network

- Caregiver sex

- Caregiver age

- Spouse caregiver

- Financial distress

- Day off work

- Interaction caregiver sex

(spousal relation) diation model.

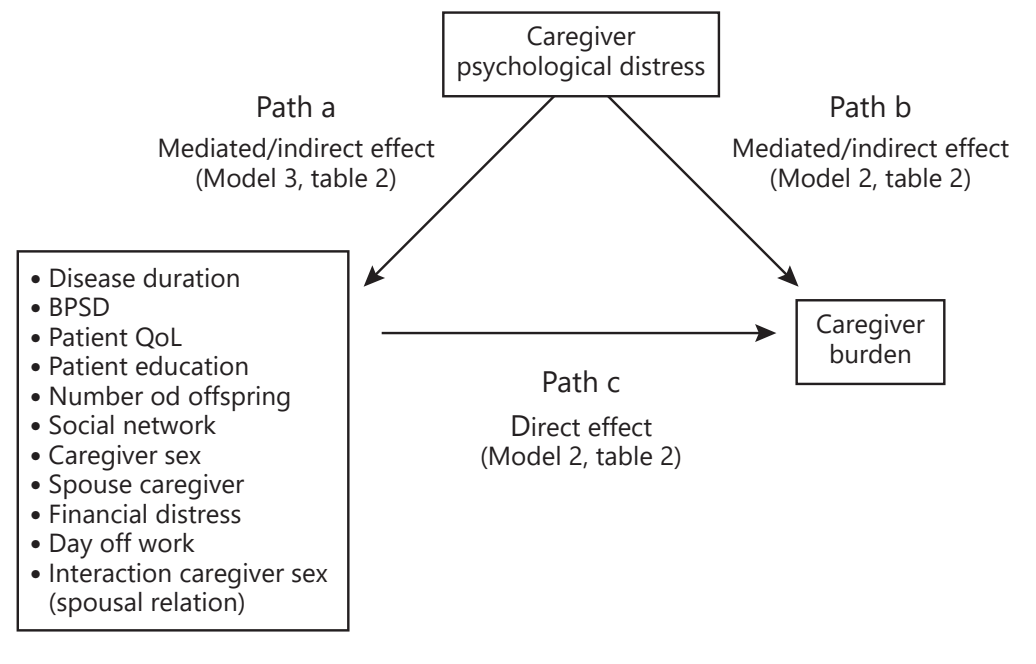

Table 3. Direct, mediated (indirect), and total effects of determinants on caregiver burden

\begin{tabular}{|c|c|c|c|c|c|c|}
\hline \multirow[t]{2}{*}{ Mediated variables } & \multirow{2}{*}{$\frac{\text { Total effect: }(C)}{\beta \text { from model } 1}$} & \multirow{2}{*}{$\begin{array}{l}\text { Direct effect: } c^{\prime} \\
\beta \text { from model } 2\end{array}$} & \multicolumn{3}{|c|}{ Indirect (mediated) effect: $a$ and $b$} & \multirow{2}{*}{$\begin{array}{l}\text { Mediation } \\
100 \%\end{array}$} \\
\hline & & & $a$ from model 3 & $b$ from model 2 & $a \times b$ & \\
\hline Financial distress & $\begin{array}{l}14.25 \\
(p=0.01)\end{array}$ & $\begin{array}{l}-0.27 \\
(p=0.94)\end{array}$ & $\begin{array}{l}4.51 \\
(p=0.00)\end{array}$ & $\begin{array}{l}3.22 \\
(p=0.00)\end{array}$ & 14.52 & $100 \%$ \\
\hline Days off work & $\begin{array}{l}-3.14 \\
(p=0.00)\end{array}$ & $\begin{array}{l}-0.64 \\
(p=0.34)\end{array}$ & $\begin{array}{l}-0.77 \\
(p=0.00)\end{array}$ & $\begin{array}{l}3.22 \\
(p=0.00)\end{array}$ & -2.5 & $100 \%$ \\
\hline Disease duration & $\begin{array}{l}-0.459 \\
(p=0.000)\end{array}$ & $\begin{array}{l}-0.134 \\
(p=0.22)\end{array}$ & $\begin{array}{l}-0.101 \\
(p=0.00)\end{array}$ & $\begin{array}{l}3.22 \\
(p=0.00)\end{array}$ & -0.325 & $100 \%$ \\
\hline Caregiver sex $\times$ spouse caregiver & $\begin{array}{l}-39.93 \\
(p=0.058)\end{array}$ & $\begin{array}{l}-17.44 \\
(p=0.205)\end{array}$ & $\begin{array}{l}-6.98 \\
(p=0.022)\end{array}$ & $\begin{array}{l}3.22 \\
(p=0.00)\end{array}$ & 22.48 & $100 \%$ \\
\hline
\end{tabular}

( $p$ values). $C=c^{\prime}+a \times b$.

nificant in explaining caregiver burden in model 1 totally lost their significance, suggesting that their effect on burden was entirely mediated by caregiver psychological distress. Table 2 reports the above models explaining the mediation paths depicted in Figure 1.

Caregiver Burden in Early-Onset

Dementia
Table 3 shows total, direct, and indirect (i.e., mediated) effects for the independent variables. The effect of disease duration, being a wife caregiver, number of caregiver days off work, and financial distress was totally mediated by caregiver psychological distress as the probability of a di- 
rect effect was not significantly different from zero. Longer disease duration, being a female spouse or partner, and having more days off work reduced the caregiver's distress and consequently the burden. At the same way, financial distress increased the psychological distress and consequently the burden. Conversely, diagnostic delay, caregiver age, and of proxies of family or social network had 100\% direct effect on caregiver burden.

\section{Discussion}

We report the first comprehensive analysis of the determinants of burden in caregivers of patients with EOD.

Caregiver burden was found to have the strongest association with caregiver sex compared to the other determinants. Specifically, the highest levels of burden were found in female caregivers. This is consistent with the findings of a recent study on caregivers of young FTD patients [23], but not with a review conducted on caregivers of all-age dementia [33]. However, being a wife caregiver (i.e., a female spouse/partner) mitigated the negative effects of being a woman on burden. In fact, burden was the highest in sisters and daughters, intermediate in wives, and the lowest in men. This is probably related to the fact that compared to wives, daughters and sisters may already have their own family responsibilities besides EOD patient caregiving, thus further enhancing the burden of patients' caregiving. Moreover, the reduction of caregiver's distress related to being a female spouse or partner can be related also to the higher likelihood that such a caregiver might already be accustomed to the role of caring for others as the main carer in the family [34]. Consequently, the cases in whom the caregiver is a sister or a daughter of the patient are those without wife/partner; thus, as an example, the daughter is less likely to receive support in caring for her children, whereas cases in whom the wife/partner is the main carer may possibly have more than one female caregiver so that the wife/partner can rely on the support from other family members. These results differ from another study on EOD examining FTD caregiver burden [35], which found no differences in burden between spouses and children. However, the study was conducted in Australia, that is, in a very different social context and used online surveys rather than face-to-face interviews.

Interestingly, in our study, the effect of being a wife was entirely mediated by the psychological component of burden. This is probably related to the stereotypical attribution of a caring role to women and particularly to wives in the family, which contributes to create higher expectations and consequently psychological distress in wives, although we found that wives were more resilient caregivers compared to other female caregivers.

Among potential clinical factors, our study confirmed the role of BPSD in increasing caregiver burden shown in previous studies, probably related to difficulties in managing disruptive behaviors [24-26]. We also identified diagnostic delay as a cause of increased burden, the effect of which was entirely nonpsychological. Spending a long time without an explanation for the patients' symptoms has practical rather than psychological consequences, possibly related to the money spent to reach the diagnosis and the time taken to other activities. This is particularly true for EOD patients that frequently have longer diagnostic delay compared to late-onset dementia [5].

Caregiver burden was also positively related to financial distress, that is, the caregiver complaint of having not enough money to afford the patient's caregiving. In fact, EOD frequently occurs in patients still actively engaged in working life with significant impact on employment [7]. In our cohort, $26 \%$ of the patients had retired because of dementia and $13 \%$ were still working but facing the possibility of leaving work. This suggests that the perception of a reduced income associated with increasing expenses increases caregiver distress, hence burden. However, contrarily to what we had hypothesized, the effect of financial distress on burden was entirely mediated by psychological components of burden. This may be related to the subjective variable used to measure financial hardship and its interaction with psychological difficulties including psychological distress. Experiencing financial hardship has been indeed found to be related to a higher risk of developing mental health problems [36].

The duration of the disease at the time of interview was negatively related to caregiver burden, and this effect was entirely mediated by psychological distress. This might be explained by the fact that a long time spent in caregiving allows people to successfully adopt coping strategies and to organize family life in a more effective way. Moreover, extended duration can also be related to caregivers' improved health literacy and training to specific EOD patients' needs developed through medical or social support that have been found to be associated with caregivers' care ability [37].

Another factor reducing the burden was found to be older caregiver age. An older caregiver is more likely to be retired and does not have to struggle in conciliating working and caregiving commitments. For spouse caregivers, these factors also imply the possibility to share caregiving with an adult instead of young children. 
Among the social factors, having taken days off work also reduced the burden, by exclusively reducing the psychological distress. This factor can also be related to a better working environment in terms of work-life balance policies including the possibilities of taking extended leaves. Family-friendly policies have been found to positively affect the effectiveness of working caregivers in both their work and family roles with a positive impact on their overall wellbeing (this has been found for working mothers, see [38]).

The robustness of the family network, measured by the number of adult children, as well as the robustness of the social network, inferred by the fact that the patients still live in the region where they were born in, also reduced caregiver burden. Both these determinants were not mediated by psychological distress suggesting that they act on the more practical and organizational components of burden. Being born and raised in the Emilia Romagna region in which the health and social services are capillary warrants a higher awareness of the right to have access to the facilities they are entitled to have through social capital development [39] and the positive effect that the higher availability of health services can have on their demand [40].

Another factor found to reduce caregiver burden is the patient's quality of life as perceived by the caregiver. This is probably the result of the empathic relationship linking the caregiver to the patient, resulting in a higher distress if the caregiver perceives a low quality of life of their loved one.

Finally, the patients' educational attainment is negatively related to caregiver burden. Although this is difficult to interpret given the fact that only the patients' education and not the caregivers' education is negatively related to burden, we argue that the educational attainment might be a proxy of the cultural, social, and economic status of the whole family, with a higher status allowing the whole family to better cope with the psychological distress related to the disease and hence to have a reduced burden.

Knowing if a burden determinant acts on the psychological or nonpsychological components of burden gives more opportunities to tackle the problem. For instance, a reduction of the burden can be obtained either directly, by means of psychological counseling, or indirectly, by increasing the number of caregiver's days off work, the final result being in both cases a reduction of caregiver burden. More importantly, interventions aimed at reducing caregiver's psychological distress might allow to reverse, albeit indirectly, the effect of apparently nonmodi- fiable determinants (e.g., caregiver sex) on burden. In addition, as some determinants are independent from psychological distress and are entirely modifiable, direct actions should be made to reduce their effect on burden, namely, to widen social networks and to reduce diagnostic delay.

A major strength of our study is related to the comprehensive analysis of several determinants exploring areas related to demographic, clinical, and socioeconomical aspects through in-depth face-to-face structured interviews. Moreover, we were able to separate the determinants having a nonmediated effect on external, nonpsychological components of burden from those mediated by psychological distress, thus allowing to explore multiple (direct or indirect) strategies of intervention. Another strength of our study was that differently from previous studies, we did not exclude patients with more severe dementia, allowing to capture caregiving difficulties along all the progression of the disease. However, our study also has several limitations: Although we studied several possible clinical and demographic factors, we could only include proxies of social and financial factors and did not consider some possibly important variables such as the specific patients' and caregivers' former job that might have had an influence on family income, nor caregivers' comorbidities that might have influenced their burden. Furthermore, the cross-sectional nature of the study may have generated reporting and recall biases in the caregivers, while the simultaneous administration of RSS and Zarit Caregiver Inventory may have possibly generated information bias.

In conclusion, with the present study, we were able to identify several determinants of caregiver burden and to identify which ones have an effect exclusively mediated by psychological distress. This should be taken into account in the organization of the interventions for EOD patients and their caregivers. These should be ultimately aimed at improving equity by increasing wellbeing and at improving efficiency by reducing the exposure for caregivers to psychological distress and related health costly treatments.

\section{Acknowledgments}

We are grateful to all the patients and their families and to the general practices that referred patients to our service and collaborated with the study. We acknowledge all the colleagues who referred patients to the present study, in particular Dr. Manuela Costa who leads the Cognitive Neurology Clinic of the Neurology Unit of Carpi Hospital (Modena, Italy). 


\section{Statement of Ethics}

The study was conducted in accordance with local clinical research regulations and conformed to the Declaration of Helsinki (Study No. 186/2016 approved by the local ethics committee). All participants had given written informed consent prior to participation.

\section{Conflict of Interest Statement}

The authors have no conflicts of interest to declare.

\section{Funding Sources}

The study was supported by a grant from the Airalzh ONLUS \& Coop Italia, the Italian Ministry of Education (MIUR), and by a grant to the Department of Biomedical, Metabolic, and Neural Sci- ences, University of Modena (Dipartimenti di eccellenza 20182022, MIUR, Italy).

\section{Author Contributions}

Annalisa Chiari was involved in conceptualization, supervision, and writing - original draft preparation. Barbara Pistoresi was involved in methodology, data analyses, software, and writing - reviewing and editing. Chiara Galli was involved in project administration, resources, data collection and curation, and investigation. Giulia Vinceti, Manuela Tondelli, and Maria Angela Molinari were involved in methodology, data collection and curation, and investigation. Tindara Addabbo was involved in supervision, conceptualization, and writing - reviewing and editing. Giovanna Zamboni was involved in conceptualization, supervision, and writing - original draft preparation.

\section{References}

1 Chiari A, Vinceti G, Adani G, Tondelli M, Galli C, Fiondella L, et al. Epidemiology of early onset dementia and its clinical presentations in the province of Modena, Italy. Alzheimers Dement. 2020;17(1):81-8.

2 Koedam EL, Pijnenburg YA, Deeg DJ, Baak $\mathrm{MM}$, van der Vlies AE, Scheltens $\mathrm{P}$, et al. Early-onset dementia is associated with higher mortality. Dement Geriatr Cogn Disord. 2008;26(2):147-52.

3 Strand BH, Knapskog AB, Persson K, Holt Edwin T, Bjertness E, Engedal K, et al. The loss in expectation of life due to early-onset mild cognitive impairment and early-onset dementia in Norway. Dement Geriatr Cogn Disord. 2019;47(4-6):355-65.

4 van Vliet D, de Vugt ME, Bakker C, Koopmans RT, Verhey FR. Impact of early onset dementia on caregivers: a review. Int $J$ Geriatr Psychiatry. 2010;25(11):1091-100.

5 Draper B, Cations M, White F, Trollor J, Loy C, Brodaty $\mathrm{H}$, et al. Time to diagnosis in young-onset dementia and its determinants: the INSPIRED study. Int J Geriatr Psychiatry. 2016;31(11):1217-24.

6 Sikes P, Hall M. The impact of parental young onset dementia on children and young people's educational careers. Br Educ Res J. 2018; 44(4):593-607.

7 Sakata N, Okumura Y. Job loss after diagnosis of early-onset dementia: a matched cohort study. J Alzheimers Dis. 2017;60(4):1231-5.

8 Beattie AM, Daker-White G, Gilliard J, Means $\mathrm{R}$. Younger people in dementia care: a review of service needs, service provision and models of good practice. Aging Ment Health. 2002; 6(3):205-12.

9 Greene JG, Smith R, Gardiner M, Timbury GC. Measuring behavioural disturbance of el- derly demented patients in the community and its effects on relatives: a factor analytic study. Age Ageing. 1982;11(2):121-6.

10 Zarit SH, Reever KE, Bach-Peterson J. Relatives of the impaired elderly: correlates of feelings of burden. Gerontologist. 1980;20(6):649-55.

11 Zarit SH, Todd PA, Zarit JM. Subjective burden of husbands and wives as caregivers: a longitudinal study. Gerontologist. 1986; 26(3):260-6.

12 Yu Y, Liu ZW, Li TX, Li YL, Xiao SY, Tebes JK. Test of the stress process model of family caregivers of people living with schizophrenia in China. Soc Sci Med. 2020;259:113113.

13 Brodaty H, Green A, Koschera A. Meta-analysis of psychosocial interventions for caregivers of people with dementia. J Am Geriatr Soc. 2003;51(5):657-64.

14 Schoenmakers B, Buntinx F, DeLepeleire J. Supporting the dementia family caregiver: the effect of home care intervention on general well-being. Aging Ment Health. 2010;14(1): 44-56.

15 Schoenmakers B, Buntinx F, Delepeleire J. Factors determining the impact of care-giving on caregivers of elderly patients with dementia. A systematic literature review. Maturitas. 2010;66(2):191-200.

16 Kimura NRS, Simões JP, Santos RL, Baptista MAT, Portugal MDG, Johannessen A, et al. Young- and late-onset dementia: a comparative study of quality of life, burden, and depressive symptoms in caregivers. J Geriatr Psychiatry Neurol. 2020:891988720933355.

17 Hvidsten L, Engedal K, Selbaek G, Wyller TB, Šaltytė Benth J, Bruvik F, et al. Quality of life of family carers of persons with young-onset compared to late-onset dementia. Aging Ment Health. 2020;24(9):1394-401.
18 Galvin JE, Howard DH, Denny SS, Dickinson $\mathrm{S}$, Tatton N. The social and economic burden of frontotemporal degeneration. Neurology. 2017;89(20):2049-56.

19 Dauphinot V, Delphin-Combe F, Mouchoux C, Dorey A, Bathsavanis A, Makaroff Z, et al. Risk factors of caregiver burden among patients with Alzheimer's disease or related disorders: a cross-sectional study. J Alzheimers Dis. 2015;44(3):907-16.

20 Liu S, Liu J, Wang X-D, Shi Z, Zhou Y, Li J, et al. Caregiver burden, sleep quality, depression, and anxiety in dementia caregivers: a comparison of frontotemporal lobar degeneration, dementia with Lewy bodies, and Alzheimer's disease. Int Psychogeriatr. 2018; 30(8):1131-8.

21 Feast A, Moniz-Cook E, Stoner C, Charlesworth G, Orrell M. A systematic review of the relationship between behavioral and psychological symptoms (BPSD) and caregiver wellbeing. Int Psychogeriatr. 2016;28(11):176174.

22 Han SH. Increasing burden of Alzheimer's disease by aging. J Korean Med Sci. 2014; 29(7):885.

23 Besser LM, Galvin JE. Perceived burden among caregivers of patients with frontotemporal degeneration in the United States. Int Psychogeriatr. 2019;31(08):1191-201.

24 Lim L, Zhang A, Lim L, Choong TM, Silva E, $\mathrm{Ng} \mathrm{A}$, et al. High caregiver burden in young onset dementia: what factors need attention? J Alzheimers Dis. 2018;61(2):537-43.

25 Feast A, Orrell M, Charlesworth G, Melunsky N, Poland F, Moniz-Cook E. Behavioural and psychological symptoms in dementia and the challenges for family carers: systematic review. Br J Psychiatry. 2016;208(5):429-34. 
26 Mioshi E, Foxe D, Leslie F, Savage S, Hsieh S, Miller L, et al. The impact of dementia severity on caregiver burden in frontotemporal dementia and Alzheimer disease. Alzheimer Dis Assoc Disord. 2013 Jan-Mar;27(1):68-73.

27 Ducharme F, Kergoat MJ, Antoine P, Pasquier F, Coulombe R. The unique experience of spouses in early-onset dementia. Am J Alzheimers Dis Other Demen. 2013;28(6):63441.

28 Bachner YG, O’Rourke N. Reliability generalization of responses by care providers to the Zarit Burden Interview. Aging Ment Health. 2007;11(6):678-85.

29 Cummings JL. The Neuropsychiatric Inventory: assessing psychopathology in dementia patients. Neurology. 1997;48(5 Suppl 6):S106.

30 Galasko D, Bennett D, Sano M, Ernesto C, Thomas R, Grundman M, et al. An inventory to assess activities of daily living for clinical trials in Alzheimer's disease. The Alzheimer's Disease Cooperative Study. Alzheimer Dis Assoc Disord. 1997;11(Suppl 2):S33-9.
31 Logsdon RG, Gibbons LE, Mccurry SM, Teri L. Quality of life in Alzheimer's disease: patient and caregiver reports. J Ment Health Aging. 1999;5:21-32.

32 Linn BS, Linn MW, Gurel L. Cumulative illness rating scale. J Am Geriatr Soc. 1968; 16(5):622-6.

33 Del-Pino-Casado R, Rodríguez Cardosa M, López-Martínez C, Orgeta V. The association between subjective caregiver burden and depressive symptoms in carers of older relatives: a systematic review and meta-analysis. PLoS One. 2019;14(5):e0217648.

34 Istat. I tempi della vita quotidiana. Lavoro, conciliazione, parità di genere e benessere soggettivo. 2019.

35 Kaizik C, Caga J, Camino J, O’Connor CM, McKinnon C, Oyebode JR, et al. Factors underpinning caregiver burden in frontotemporal dementia differ in spouses and their children. J Alzheimers Dis. 2017;56(3):1109-17.
36 Kiely KM, Leach LS, Olesen SC, Butterworth $\mathrm{P}$. How financial hardship is associated with the onset of mental health problems over time. Soc Psychiatry Psychiatr Epidemiol. 2015;50(6):909-18.

37 Li Y, Hu L, Mao X, Shen Y, Xue H, Hou P, et al. Health literacy, social support, and care ability for caregivers of dementia patients: structural equation modeling. Geriatr Nurs. 2020;41(5):600-7.

38 Javed U. Combining career and care-giving: the impact of family-friendly policies on the well-being of working mothers in the United Kingdom. Global Business Organizational Excell. 2019;38:44-52.

39 Ehsan AM, De Silva MJ. Social capital and common mental disorder: a systematic review. J Epidemiol Commun Health. 2015; 69(10):1021-8.

40 Andersen R, Newman JF. Societal and individual determinants of medical care utilization in the United States. Milbank Mem Fund Q Health Soc. 1973;51(1):95-124. 